NASA Technical Memorandum 100432

\title{
Development of a Real-Time Aeroperformance Analysis Technique for the X-29A Advanced Technology Demonstrator
}

R.J. Ray, J.W. Hicks, and R.I. Alexander

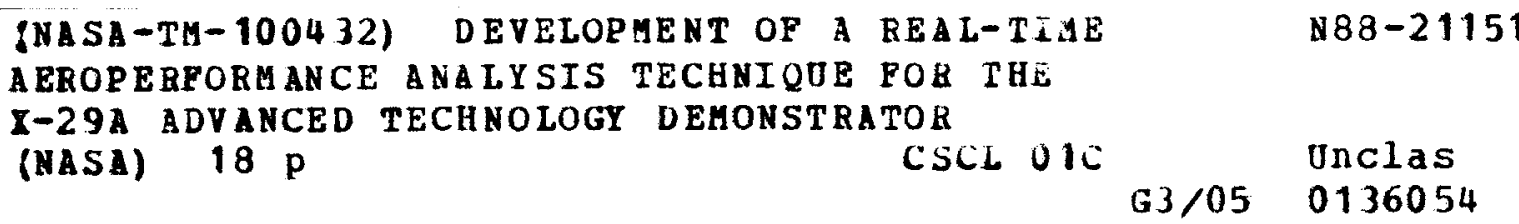

May 1988 


\section{Development of a Real-Time Aeroperformance Analysis Technique for the X-29A Advanced Technology Demonstrator}

R.J. Ray, J.W. Hicks, and R.I. Alexander

Ames Research Center, Dryden Flight Research Facility, Edwards, California

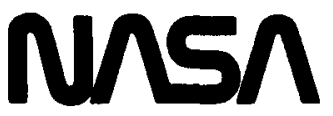

National Aeronautics and

Space Administration

Ames Research Center

Dryden Flight Research Facility

Edwards, California 93523.5000 
DEVELOPMENT OF A REAL-TIME AEROPERFORMANCE ANALYSIS TECHNIQUE FOR THE $X$-29A AUVANCED TECHNOLOGY DEMONSTRATOR

$$
\begin{aligned}
& \text { R.J. Ray and J.W. Hicks } \\
& \text { NASA Ames Research Center } \\
& \text { Dryden Flight Research Facility } \\
& \text { Edwards, California }
\end{aligned}
$$

R.I. Alexander*

Computing Devices Co.

Ottawa, Canada

\section{Abstract}

The $X-29 A$ advanced technology demonstrator has shown the practicality and advantages of the
capability to compute and display, in real time, aeroperformance flight results. This capability includes the calculation of the in-flight measured drag polar, lift curve, and aircraft specific excess power. From these elements, many other types of aeroperformance measurements can be computed and analyzed. The technique can be used to give an immediate postmaneuver assessment of data quality and maneuver technique, thus increasing the productivity of a flight program. A key element of this new method was the concurrent development of a real-time in-flight net thrust algorithm, based on the simplified gross thrust method. This net thrust algorithm al lows for the direct calculation of total aircraft dray.

\section{Nomenclature}

A

$C_{D}$

$C_{L}$

ComDev Computing Devices Company

c.g. center of gravity

D aircraft drag, ib

DNOZ , external nozzle drag, lb

Dspil inlet spillage drag, ib

Fex excess thrust, ib

$F_{G} \quad$ gross thrust, 1b

FM frequency modulation

$F_{N}$ engine net thrust available, ib

FNP net propulsive force, Ib

$F_{R} \quad$ ram drag, ib

FVG fan variable guide vanes

HPVG high-pressure compressor variable guide vanes
IRP

L

M

$n_{x}$

$n_{y}$

$n_{\mathbf{z}}$

N1

N2

P

p

p

$P_{\text {S }}$

PLA

PCM

PSL

qbar

$\mathbf{q}$

q

$r$

$\dot{r}$

RIG

S

SGTM

SNTM

$T$

$v_{t}$

W intermediate rated power (83 < PLA < $87 \mathrm{deg}$ )

aircraft lift, ib

Mach number

aircraft longitudinal acceleration, $y$

aircraft lateral acceleration, $g$

aircraft normal acceleration, $g$

fan rotor speed, rpm

compressor rotor speed, rpm

pressure, psi

roll rate, deg/sec

roll acceleration rate, $\operatorname{deg} / \mathrm{sec}^{2}$

specific excess power, $\mathrm{ft} / \mathrm{sec}$

power lever angle, deg

pulse code modulation

Propulsion System Laboratory

(NASA Lewis)

dynamic pressure, psi

pitch rate, deg/sec

pitch acceleration, deg/ $\mathrm{sec}^{2}$

yaw rate, deg/sec

yaw acceleration rate, deg/ $/ \mathrm{sec}^{2}$

real-time interactive graphics system

reference wing area, $\mathrm{ft}^{2}$

simplified gross thrust method

simplified net thrust method

temperature, ${ }^{\circ} \mathrm{C}$

true airspeed, $\mathrm{ft} / \mathrm{sec}$

mass flow rate, $\mathrm{Ib} / \mathrm{sec}$

\footnotetext{
*Aerospace engineer.
} 


$$
\begin{array}{ll}
\text { Wt } & \text { aircraft gross weight, ib } \\
\alpha & \text { angle of attack, deg } \\
\sigma & \text { standard deviation, percent } \\
\text { B } & \text { angle of sideslip, deg }
\end{array}
$$

Subscripts

$\begin{array}{ll}\text { AB } & \text { afterburner } \\ \text { AP } & \text { area-pressure thrust method } \\ \text { b } & \text { body axis } \\ \text { B3 } & \text { engine compressor bleed air } \\ \text { P } & \text { primary } \\ \text { F } & \text { fuel } \\ \text { i } & \text { indicated } \\ \text { S } & \text { static } \\ \text { T } & \text { total } \\ \text { W } & \text { wind axis } \\ \text { WT } & \text { mass-flow thrust method }\end{array}$

Engine Stations

$\begin{array}{ll}0 & \text { free stream } \\ 1 & \text { engine inlet } \\ 3 & \text { compressor exit } \\ 5 & \text { turbine rotor discharge } \\ 558 & \text { turbine exhaust exit } \\ 6 & \text { afterburner inlet } \\ 7 & \text { exhaust nozzle inlet } \\ 8 & \text { exhaust nozzle throat } \\ 9 & \text { exhaust nozzle exit }\end{array}$

\section{Introduction}

Aircraft performance flight test data has traditionally been calculated and analyzed after the test flight has ended. This postflight analysis often has revealed errors and other inadequacies in the data that were serious enough to require that the flight test be repeated. The capability to calculate and display performance data for ground monitoring while a flight was still in progress would significantly improve flight productivity by allowing rapid and accurate real-time evaluation of flight test maneuver techniques and data quality. If the data from a maneuver were judged to be unacceptable, the maneuver could be repeated immediately while flight test conditions were suitable.

Because of the limited test time available during the $X-29 A$ flight test program to define the performance potential of the forward-swept wing and its related technologies, the need for a realtime performance data analys is capability was especially critical. This real-time capability, coupled with dynamic flight maneuver techniques, would also provide a way to assess maneuver dynamic effects and instrumentation system malfunctions. Safety of flight monitoring capability would also be improved. Previous efforts have proven the benefits of real-time analysis techniques. 1

This paper describes a real-time aeroperformance analysis capability developed at the NASA Ames-Dryden Flight Research Facility to calculate and display in graphical form aerodynamic data such as drag polars and lift curves along with engine performance parameters. Integral to this capability was the development of a real-time inflight net thrust algorithm based on the simplified gross thrust method (SGTM) of the Computing Devices Company (ComDev) of Ottawa, Canada. ${ }^{2}$ This new technique was developed, under a joint agreement between the United States and Canada, using data obtained during the thrust calibration test of the $X-29 A$ 's performance engine at the NASA Lewis Research Center's Propulsion System Laboratory (PSL). 3 Typical flight results are presented along with an assessment of the in-flight uncertainty of the real-time net thrust method.

\section{Aircraft Description}

The $X-29 A$ (Fig. 1) is a single-seat fightertype aircraft incorporating several new technology concepts that integrally work together for aircraft performance improvements. The most notable feature is the forward-swept wing with a $29.3^{\circ}$ leading edge sweep and a 5 percent thin supercritical airfoll section. The upper and lower surface wing skins are made of a graphite-epoxy composite material and are aeroelastically tailored to inhibit wing structural divergence. The wing has no leading edge devices, but incorporates full-span trafling edge, dual-hinged flaperons that are divided into three segments on each wing. Wing camber is automatically controlled by the flight control system.

Another feature of the aircraft is its active three-surface pitch control configuration. In addition to the wing flaperons, this configuration included the canards and the aft-mounted strake flaps. Symmetric deflection of these fully active surfaces is controlled by the flight control system to provide trim and pitch stability and control. The canards are 20 percent of the wing area and act as a powerful lift and pitch generator. The strake flaps assist the canards in trimming the flaperons to control aerodynamic loading of the canard. Differential deflection of the flaperons provides the sole source of roll control. Yaw control is provided by a single-piece rudder mounted on a fixed vertical stabilizer.

The aircraft's 35 percent negative static margin requires a high level of stability augmentation which is provided by a tri-ply redundant digital fly-by-wire flight control system with an analog backup. The flight control system controls wing camber by the automatic camber control mode, 
which sets the optimum schedule as a function of Mach number and angle of attack, or by the manual camber control mode, which is set in discrete $5^{\circ}$ intervals selected by the pilot. In the automatic camber control mode, the flaperons vary the camber of the wing to increase aerodynamic efficiency over the flight envelope. The automatic camber control mode also positions the canards and strake flaps along with the wing flaps to trim pitching moments and to give the best aerodynamic performance in steady-state flight. The manual camber control mode was designed only as a flight test mode. A more detailed description of this system can be found in Gera. 4

The aircraft is powered by a single 16,000-1b class General Electric (Lynn, Massachusetts) F404-GE-400 afterburning engine. The engine is mounted in the fuselage with two side-mounted, fixed geometry inlets that were optimized for transonic performance. Maximum aircraft takeoff gross weight is 17,800 ib with a 4,000-1b fuel capacity in two fuselage and two strake tanks.

\section{Data Acquisition System}

The $X-29 A$ on-board data acquisition system uses both pulse code modulation (PCM) and frequency modulation (FM) for data encoding. A schematic of the instrumentation system can be seen in Fig. 2. Because of space constraints, no data was recorded on the aircraft. The 10-bit PCM system sampled data from 25 to 400 samples per sec, depending on the desired frequency range to be covered. The digital data were processed by five PCM units, and an interleaver device merged the data stream along with the output from the flight control computer's bus. The data were telemetered as an uncalibrated serial PCM stream. The constant-bandwidth FM system was installed to process high-response acceleration and vibration data. This FM signal was merged with the rest of the digital data from the interleaver and telemetered to the ground along with the pilot's voice signals. A total of 691 measured data parameters was telemetered to the ground for recording, real-time analysis, and control room monitoring. The data parameter set included measurements for structural loads, structural dynamics, flight controls, stability and control, aircraft subsystems, propulsion and performance, wing deflections, buffet, and external pressure distributions.

Aircraft instrumentation included a pitotstatic noseboom with angle of attack, $\alpha$, and sideslip angle, $\beta$, vanes. The instrumentation package used for the flight performance measurements included two body-mounted linear accelerometer packages, and a rate gyro package for aircraft pitch, roll, and yaw attitudes, rates, and angular accelerations. One linear accelerometer set, termed the dynamic performance center-ofgravity (c.g.) package, had limited measurement ranges specifically tailored to the pushoverpullup maneuver described later in this paper. Its longitudinal and lateral accelerometer ranges were $\pm 0.6 \mathrm{~g}$ and the normal accelerometer range was -1 to $+3 \mathrm{~g}$. The other accelerometer set, termed the center-of-gravity accelerometer package, had larger accelerometer ranges varying from $\pm 1 \mathrm{~g}$ for the longitudinal and lateral accelerometers and
-3 to $+8 \mathrm{~g}$ for the normal accelerometer. This covered the higher $\alpha$ range data. Both packages were displaced from the actual aircraft center of gravity.

The General Electric F404-GE-400 engine has a complete instrumentation system for monitoring engine operating characteristics, engine trim levels, and for calculating in-filight thrust. Measurement locations are shown in Fig. 3 and included inlet total temperature, $\mathrm{T}_{\mathrm{T}_{1}}$, fan and compressor rotor speeds, N1 and N2, combustor static pressure, $P_{S_{3}}$, turbine exhaust temperature,

$T_{T_{5}}$, nozzle throat area, $A_{8}$, and a 20-probe rake measurement of turbine exhaust pressure, $\mathrm{P}_{558^{*}}$ Volumetric flow meters were used to measure main engine fuel flow, $W_{F p}$, and afterburner pilot and main fuel flows, $W_{F_{A B}}$.

In order to implement the real-time in-flight thrust method discussed in this paper, four flushmounted static pressure taps were located at both the afterburner entrance, $P_{S_{6}}$, and exhaust nozzle entrance, $P_{S_{7}}$. This technique also made use of the engine $\mathrm{P}_{\mathrm{T}_{558}}$ rake, $\mathrm{T}_{\mathrm{T}_{5}}$, free stream static air pressure, ${ }^{P} S_{0}$, and true airspeed, $V_{t}$.

\section{Real-Time Data Processing and Display}

The $x-29 A$ real-time performance data system is designed to record data from the aircraft data aquisition system, then process and display the information in the mission control room. An illustration of this system is shown in Fig. 4. Data from the aircraft is transmitted in a serial PCM stream and received by the telemetry tracking facility on the ground. The data stream is then passed along land lines to a mission control center for data storage, processing, and display. These facilities make up part of the NASA Dryden Western Aeronautical Test Range. 5

For security reasons, $X-29 A$ flight data is telemetered in an encrypted format. The serial data is decrypted, synchronized, and demultiplexed in the mission control center. An analog tape recorder is used to store this raw aircraft data for postflight processing. The raw data is also passed to a Gould 32/67 computer system (Gould Inc., Fort Lauderdale, Florida) with dual processing capability for real-time computing and application of engineering-unit calibrations. Processed data from the real-time computer is formatted for display on various devices in the mission control room. Display devices include CRT, analog stripcharts and gages, and a realtime interactive graphics (RIG) system.

The RIG system allows an operator to control the display of real-time color graphics during flight test. For the $X-29 A$, the real-time performance system used the RIG capability to display various performance plots such as the drag $\left(C_{D}\right.$ vs $\left.C_{L}\right)$, the lift curve $\left(C_{L}\right.$ vs $\left.\alpha\right)$, and specific excess power ( $P_{S}$ vs Mach number). An example RIG dis- 
play format is shown in Fig. 5. The digital data included aircraft-measured accelerations, calculated body axis accelerations corrected to the c.g., translated wind axis accelerations, and aircraft flight conditions, attitudes, and rates. Displays were also developed to monitor engine parameters and performance, including time histories of gross and net thrust, and the pressure rake averages. The ComDev thrust displays included digital parameters such as basic engine parameters critical to flight safety, along with engine performance parameters. Logic was also developed to monitor continually the status of the Comper thrust calculation methods and to display a coded message when an error occurred, describing the nature of the error.

The RIG system stores a number of predefined display formats that can be selected by the operator as required. Graphic parameters are updated at up to 10 samples per sec and the column of digital data displayed next to the graphics is updated at one sample per sec. The actual calculation rate of the performance parameters is up to 12.5 samples per sec. The RIG operator not oniy controls which graphic page (format) to display, but also can start, stop, clear, and print the display at any time. Future plans include upgrading the RIG system with a new system capable of creating and changing graphic formats, colors, and parameters in real time.

\section{Development of a Real-Time Net Thrust Algorithm}

Over the past 15 years, ComDev has developed and patented a unique capability to compute accurately engine gross thrust in real time over the entire aircraft operating flight envelope. This simplified gross thrust method (SGTM) has been evaluated successfully for a variety of variable exhaust turbojet and turbofan fighter engines. NASA has evaluated the SGTM on the $F 100^{2}$ and $J 85$ engines 6 and flown it in an F-15 aircraft. 7

The SGTM has advantages over the traditional methods, such as the manufacturer's in-flight thrust program, in that it requires much less instrumentation and computational power while remaining reliable and accurate. It requires only free-stream static air pressure, $P_{S_{0}}$, and simple gas pressure measurements at three locations in the engine afterburner duct (Fig. 4). Because all engine pressures are measured downstream of the rotating machinery, gross thrust accuracy is not affected by engine degradation or intake distortion.

The SGTM computes gross thrust based on a onedimensional analysis of the flow in the engine afterburner and exhaust nozzle. Figure 6 shows a block diagram of the algorithm. The algorithm analyzes the flow in the afterburner duct from the turbine exit (station 558) to the exhaust nozzle exit (station 9) and determines first the total pressure at the afterburner entrance, $P_{T_{6}}$, and then at the exhaust nozzle entrance, $\mathrm{P}_{77}$. The exhaust nozzle throat area, $A_{8}$, is also computed. Gross thrust is then computed from the calculated value of $\mathrm{PT}_{7}$ and $A_{8}$ and measured nozzle static pressure. The SGTM also computes exhaust nozzle exit area, $A_{9}$, by applying computed $A_{8}$ and the mechanical $A_{9} / A_{8}$ schedule.

Calibration coefficients for the F404 engine were determined using data obtained during testing at the Lewis PSL facility. Pressure and thrust data were collected from 131 data points at 11 combinations of Mach number and altitude over the range of engine power settings from near flight idle to maximum afterburning. The coefficients were applied to the equations to correct for the effects of internal friction, mass transfer (leakages), three-dimensional effects, and the effect of the simplifying assumptions used in the theory. Calibration coefficients obtained through calibration of the individual engine provide good accuracy for all engines of the same model.

Computing Devices Company has developed an accurate and fast net thrust algorithm for the F404 engine. A block diagram of the simplified net thrust method (SNTM) is shown in Fig. 7. The SNTM uses the same $P_{S_{6}}$ and $P_{S_{7}}$ pressure measurements as the SGTM and also uses the production $\mathrm{T}_{5}$ measurement and calculated true velocity, $V_{t}$. No additional instrumentation is required to compute net thrust using the SNTM.

Net thrust, $F_{N}$, is defined as gross thrust, $F_{G}$, minus inlet airflow momentum or ram drag, $F_{R}$.

$$
F_{N}=F_{G}-F_{R}
$$

Ram drag is defined as the product of $V_{t}$ and mass flow rate, $W_{1}$.

$$
F_{R}=V_{t} W_{1} / g
$$

The ComDev SGTM calculates $F_{G}, P_{T_{6}}$, and $A_{9}$. The SNTM calculates $W_{1}$ and obtains $V_{t}$ from the aircraft air data system to determine ram drag and thus net thrust.

Inlet mass flow is determined by calculating mass flow rate at the afterburner entrance (station 6), using flow parameters determined in the SGTM gross thrust algorithm and the turbine discharge total temperature measured by existing engine instrumentation. This mass flow rate, $W_{6}$, is used to compute the inlet mass flow rate after accounting for compressor bleed air extraction, $W_{B 3}$, and fuel mass addition, $W_{F}$, using an empirical model calibrated with test data from the Lewis PSL facility. The inlet mass flow is thus computed by

$$
W_{1}=w_{6}-W_{F}+W_{B 3}
$$

The SNTM calculates engine station 6 local Mach number, $M_{6}$, and mass flow rate, $W_{6}$, using measured $\mathrm{T}_{5}$ and $\mathrm{P}_{\mathrm{S}_{6}}$, and calculated $\mathrm{P}_{6}$. Total temperature at station $6, T_{T_{6}}$, is assumed to equal 
$T_{T_{5}}$. A simplified main engine fuel flow, $W_{F}$, in comparison to calculated inlet airflow relationship, was derived empirically from Lewis PSL facility data.

A constant bleed air extraction, $W_{B 3}$, was assumed based on aircraft system cooling air requirements. Over the aircraft operating envelope, the flows $W_{F}$ and $W_{B 3}$ are much smailer than $W_{6}$ (typically less than 2 percent of $W_{6}$ ). Therefore, errors in their determination have only secondary effects on $W_{1}$ accuracy. The accuracy of the production engine mounted $\mathrm{T}_{5}$ measuring system is adequate because the sensitivity of computed net thrust to $T_{T_{5}}$ errors is small. A $10^{\circ} \mathrm{F}$ error in $T_{T_{5}}$, for example, produces an error of only 0.03 percent in net thrust at intermediate rated power (IRP) at Mach $0.9,30,000 \mathrm{ft}$.

The SNTM was calibrated against Lewis PSL data over the X-29A Mach, altitude, and power setting envelope. Calibration coefficients were applied to correct for the effects of the simplifying assumptions in the net thrust calculation.

Because the mass flow is calculated in the engine afterburner section, where the gas flow is well mixed, inlet flow distortion effects are minimized.

\section{Data Analysis Method}

Using the accelerometer data inputs, the drag polar analysis technique included body-axis accelerometer angular rate and acceleration corrections to the aircraft c.g. Accelerometer data were transformed to the aircraft wind axis or flight path system by angular transformations through $a$ and $B$. Thrust installation corrections included estimated nozzle drag, $D_{N O Z}$, and spillage drag, DSPIL.

Aircraft coefficients of lift $\left(C_{L}\right)$ and drag $\left(C_{D}\right)$ were computed from the accelerometer method 8 using the equations

$$
\begin{aligned}
& C_{D}=\frac{D}{\text { qbar } S}=\frac{F_{N P}-F_{e x}}{\text { qbar } S} \\
& C L=\frac{L}{\text { qbar } S}=\frac{n_{Z} W t-F_{G} \sin \alpha}{\text { qbar } S}
\end{aligned}
$$

where

$$
\begin{aligned}
& F_{\text {ex }}=n_{x} w t \\
& F_{N P}=F_{N}-\left(D_{S P I L}+D_{N O Z}\right)
\end{aligned}
$$

Afrcraft $P_{S}$ was computed from the accelerometer data as follows:

$$
P_{s}=F_{\text {ex }} V_{t} / W t
$$

The input data to the real-time performance program were not filtered (except for an on-board, anti-allasing filter for acceleration parameters), nor were trim drag corrections applied to the drag results. The real-time display values were neither smoothed nor thinned (below the 10 samples per sec update rate of the RIG system), and wild points were netther edited nor removed. This allowed the fastest calculation rate possible in real time and the ability to evaluate data quality without the extra data massaging. The time lag between the actual flight event and the display of calculated performance data on the RIG is estimated to be under $0.25 \mathrm{sec}$. The abovementioned data reduction techniques are a part of the postflight processing.

Real-time software was developed to implement the aircraft and engine performance analys is techniques. Figure 8 summarizes the performance calculations in a flow diagram. The X-29A air-data software was used to obtain $\alpha$ and $B$ and Mach number, $M$. Indicated angle of attack, $\alpha_{i}$, was corrected for upwash errors, misalignment errors, pitch rate effects, boom bending, and fuselage bending effects. Mach number was computed from nose boom pitot static measurements.

A pressure averaging routine was developed to process engine pressure rake data. The average pressure of each rake is calculated using all the available probes. A comparison is then made between each individual probe and the average pressure. Those probes outside of a specified tolerance of the average are assumed bad and eliminated. A new average rake pressure is then calculated. If all the probe values of one rake are outside the specified tolerance, the highest and lowest probe values are eliminated, the rake average is calculated again, and the tolerance check is repeated. This technique yields highquality pressure data, even in the event of damaged pressure lines, fauity transducers, or data transmission problems. This routine also expedited the implementation, checkout and troubleshooting of the engine pressure rake instrumentation system.

\section{Maneuver Techniques}

Dynamic flight test techniques were used to define quickly and accurately the aircraft drag polar and lift curve characteristics at a given Mach number over a wide range of $\alpha$. These maneuver techniques rely on accelerometer methods using body-mounted accelerometer packages to measure aircraft accelerations along and normal to the flight path.

Two dynamic maneuvers, the pushover-pullup and the windup turn, were used on the $x-29 A$ to define complete drag polar curves. Both maneuvers were preceded by $30-\mathrm{sec}$ stabilized trim points. The pushover-pullup was used to obtain the mid- to lowrange of $a$. The maneuver test technique consisted of a pushover from the $1 \mathrm{-g}$ normal load factor, $n_{z}$, at the stabilized flight condition to zero $g$ 's at a nominal g-onset rate of $-0.2 \mathrm{~g}$ 's per sec. At the zero-g point, the aircraft was pulled up at a 0.2 $g$ 's per sec onset rate to $2 \mathrm{~g}$ 's and then returned to the $1-g$ level flight condition. Altitude and Mach number excursions were kept to a minimum while power lever angle (PLA) was held constant. The wind-up turn maneuver was used to obtain data from the mid- to high-range of $\alpha$. Using the same gonset rate as for the pushover-pullup maneuver, 
the windup turn was flown at a fixed power setting with the aircraft descending, trading altitude for airspeed in order to hold a constant Mach number as the normal load factor and a were increased to the aim conditions. For a given Mach number, the maneuvers produced flight data that overlapped in coefficient of lift between 1 and $2 \mathrm{~g}$ 's, giving a full polar shape over $\alpha$ and assuring good data correlation between the maneuvers. Figure 9 gives a schematic drag polar representation of the maneuvers sweep of the $\alpha$ variation of a polar at a constant Mach number. Further discussions of the $X-29 A$ flight test techniques can be found in Hicks and others. 9

\section{Results and Discussion}

\section{Net Thrust Uncertainty}

An analysis was conducted to determine the accuracy of the real-time performance values as affected by the net thrust calculation. The net thrust values calculated by the SNTM method were compared to measured values obtained in the Lewis PSL facility. The percent error in SNTM, expressed as a percentage of measured net thrust, is plotted against PLA in Fig. 10. The bias error, over the 131 test points at 11 simulated flight conditions, was zero percent and the 95 percent statistical confidence limit (two standard deviations, $2 \sigma$ ) was \pm 2.74 percent. This spread includes contributions from all the input measurement errors and the SNTM net thrust model error determined from Lewis PSL data.

A sensitivity analysis was conducted to determine the expected in-flight uncertainty of the SNTM. Net thrust uncertainty was calculated by combining the model error and the individual errors due to the error in each input measurement (see Fig. 6) by the method of root-sum-squares. Table 1 shows the in-flight total uncertainties of SNTM net thrust for six Mach number and altitude conditions at three power settings. The uncertainty at IRP ( $P L A=87^{\circ}$ ) ranges from \pm 2.41 percent at Mach $0.8,10,000 \mathrm{ft}$ to \pm 4.39 percent at Mach $0.8,40,000 \mathrm{ft}$. At Mach $0.9,30,000 \mathrm{ft}$ design point, the total uncertainty of the SNTM at IRP is \pm 3.15 percent, and, at maximum afterburning, it is \pm 2.75 percent.

These results verify that highly accurate net thrust values have been calculated in real time on the $X-29 A$ aircraft. The sensitivity of calculated lift and drag due to independent parameters such as thrust and a was evaluated for the $X-29 A$ in Powers. 10 Based on these results, the uncertainty in the real-time $C_{D}$ value due to the uncertainty in net thrust is estimated to be about \pm 3.0 percent. The effects of $\alpha$ uncertainty on $C_{L}$ and $C_{D}$ can also be substantial.

\section{Flight Results}

The use of real-time performance calculations allowed an immediate assessment of data quality and maneuver technique. Figure 11 shows typical drag polars obtained during various performance maneuvers. The pushover-pullup maneuver (Fig. 1la) sweeps out the lower a portion of the drag polar while the windup turn maneuver,
(Fig. 11b) overlaps and completes the higher $\alpha$ section of the curve as discussed in the Maneuver Techniques section of this paper. These results illustrate the data quality obtained in real time during $X-29 A$ performance testing. A maneuver that misses the aim flight conditions can be terminated and repeated immediately, greatly increasing productivity and reducing the postfight data processing requirements.

Figure 11c shows an example of a poor quality pushover-pullup maneuver which is evident by the increased data scatter compared to Fig. 11a. This data scatter resulted, in part, due to improper aerodynamic surface positions caused by maneuver dynamics.11 This scatter can occur when the flight control inputs are too abrupt for the flaperons, strake flaps, or canard to follow optimum schedules. Other factors that may affect the performance maneuver quality include buffet, off Mach or altitude conditions, and pilot technique.12

The ability to monitor performance data quality and the function of the instrumentation system in real time proved a very effective diagnostic capabllity. During the initial checkout of the thrust instrumentation system, the engine pressure averaging logic helped to detect and isolate pressure leaks and transducer failures. The Combev real-time thrust algorithms also helped in the flight safety monitoring of the $X-29 A$ 's engine performance during takeoff checks and flight.

To evaluate the in-flight calculation of thrust using the SNTM, comparisons were made to the thrust values calculated by the engine manufacturer's in-flight thrust program. This postflight program computes net thrust by two methods: the area-pressure method, $F_{N_{A P}}$, and the mass flow method, $\mathrm{F}_{\mathrm{NWT}_{\mathrm{W}}} 13$ These two methods were also calibrated using Lewis PSL data.

The three net thrust methods were compared during postflight processing of over 150 performance maneuvers including windup turns, pushoverpullups, level accelerations and decelerations, stabilized level flight, and takeoff. Figure 12 shows some typical results. The three net thrust methods agreed within their expected in-flight uncertainties. For example, Fig. 12a shows flight data from a sustained high-g turn at maximum power at Mach 0.9 and 30,000 ft. Net thrust computed by the SNTM and in-flight thrust program fall within a band of \pm 2.7 percent throughout the maneuver. The thrust increase shown in this figure is due to decreasing altitude and increasing Mach during the maneuver. Flight conditions shown in this figure are target conditions. Figure $12 \mathrm{~b}$ also shows a comparison of the three thrust methods shortly following an IRP takeoff. The net thrust values show little change during the maneuver because the aircraft is both climbing and accelerating, causing a cancellation effect. Postflight comparisons show the SNTM typically falls between the $F_{N_{A P}}$ and $F_{N_{W T}}$ values as shown in Fig. $12 \mathrm{~b}$.

These results give confidence to the predicted accuracies of the SNTM presented in this paper.

The dynamic response of the SGTM calculation was evaluated by postflight methods. Time his. 
tories of measured engine parameters, average rake pressures, and computed gross thrust were plotted at the rate of 25 samples per sec for a rapid throttle movement. Figure 13 shows the typically dynamic response of the SGTM computed thrust to changes in engine operating conditions. In this example, at Mach 0.7 and 23,000 ft, the power setting was chopped from $130^{\circ}$ PLA (maximum afterburning) to $50^{\circ}$ PLA (near flight idle) in about 1 sec. Gross thrust is seen to follow closely the change in engine pressures.

\section{Concluding Remarks}

The practicality and advantages of a real-time performance analysis technique were demonstrated during flight testing of the $X-29 A$. This technique has enhanced the flight productivity and efficiency of the flight research program. It also helped to assess data quality, instrumentation functionality, and maneuver technique. A key element in the success of the real-time performance technique was the development of the Computing Devices Company's simplified net thrust method. This net thrust algorithm allows for the rapid calculation of aircraft thrust and drag and enhanced the safety of flight monitoring of the propulsion system. Because accurate net thrust values were calculated by the SNTM, the uncertainties in real-time $C_{D}$ results due to the uncertainty in net thrust were estimated to be about \pm 3 percent.

Real-time performance analysis provides a major advancement in flight test productivity and efficiency by increasing aircraft diagnostic capabilities related to aircraft performance flight testing, resulting in decreased downtime and postflight data requirements. Results show good agreement with uncertainty predictions and compare favorably to postflight techniques.

\section{References}

\footnotetext{
1Bosworth, J.T.: Real-Time Open-Loop Frequency Response Analysis of Flight Test Data. AIAA Paper 86-9738, 1986.

2Kurtenbach, F.J.: Evaluation of a Simplified Gross Thrust Calculation Technique Using Two Prototype F100 Turbofan Engines in an Altitude Facility. NASA TP-1482, 1979.
}

3Burns, M.E.; and Kirchgessner, T.A.: Airflow Calibration and Exhaust Pressure Temperature Survey of an F-404, S/N 215-209, Turbofan Engine. NASA TM-100159, 1987.

${ }^{4}$ Gera, Joseph: Dynamics and Controls Flight Testing of the X-29A Airplane. NASA TM-86803, 1986.

5GMD Systems: Western Aeronautical Test Range Systems Documentation. GMD 87-104, Lancaster, California.

6Baer-Riedhart, J.I.: Evaluation of a Simplified Gross Thrust Calculation Method for a J85-21 Afterburning Turbojet Engine in an Altitude Facility. AIAA Paper 82-1044, 1982.

7Kurtenbach, F.J.; and Burcham, F.W., Jr.: Flight Evaluation of a Simplified Gross Thrust Calculation Technique Using an F100 Turbofan Engine in an F-15 Airplane. NASA TP-1782, 1981.

8Hicks, J.W.; and Huckabone, T.: Preliminary Flight-Determined Subsonic Lift and Drag Characteristics of the X-29A Forward-Swept-Wing Airplane. NASA TM-100409, 1988.

9Hicks, J.W.; Cooper, J.M., Jr.; and Sefic, W.J.: Flight Test Techniques for the $X-29 A$ Aircraft. AIAA Paper 87-0082, AIAA 25th Aerospace Sciences Conference, Reno, Nevada, Jan. 1987.

10powers, S.G.: Predicted X-29A Lift and Drag Coefficient Uncertainties Caused by Errors in Selected Parameters. NASA TM-86747, 1985.

11 Hicks, J.W.; and Moulton, B.J.: Effects of Maneuver Dynamics on Drag Polars for an Aircraft With Automatic Wing Camber Control. AIAA Paper 88-2144, May 1988.

12Hicks, J.W.; Kania, J.; Pearce, R.; and Mills, G.: Challenges in Modeling the $X-29 A$ Flight Test Performance. AIAA Paper 87-0081, 1987.

13Burcham, F.W., Jr.: An Investigation of Two Variations of the Gas Generator Method To Calculate the Thrust of the Afterburning Turbofan Engines Installed in an F-111A Airplane. NASA TN-D-6297, 1971. 
TABLE 1. - ESTIMATED IN-FLIGHT UNCERTAINTY OF THE COMDEV SIMPLIFIED GROSS AND NET THRUST METHOUS

\begin{tabular}{ccccc}
\hline \hline \multirow{2}{*}{ Mach } & & \multicolumn{3}{c}{ Uncertainty } \\
& Altitude, ft & PLA, deg & SGTM, \% & SNTM, \% \\
\hline 0.4 & 10,000 & 70 & 2.35 & 3.61 \\
& & 87 & 1.36 & 2.41 \\
& & 130 & 0.99 & 2.10 \\
0.8 & 10,000 & 70 & 2.52 & 3.61 \\
& & 87 & 1.32 & 2.41 \\
& & 130 & 1.06 & 2.10 \\
0.9 & 30,000 & 70 & 2.61 & 4.25 \\
& & 87 & 1.48 & 3.15 \\
& & 130 & 1.05 & 2.75 \\
1.2 & 30,000 & 70 & 1.28 & 2.69 \\
& & 87 & 1.36 & 2.69 \\
& & 130 & 1.04 & 2.72 \\
0.8 & 40,000 & 70 & 2.55 & 3.65 \\
& & 87 & 1.82 & 4.39 \\
& & 130 & 1.09 & 2.86 \\
& & & & \\
1.6 & 40,000 & 70 & 1.36 & 2.81 \\
& & 87 & 1.36 & 2.81 \\
& & 130 & 1.04 & 2.74 \\
\hline
\end{tabular}
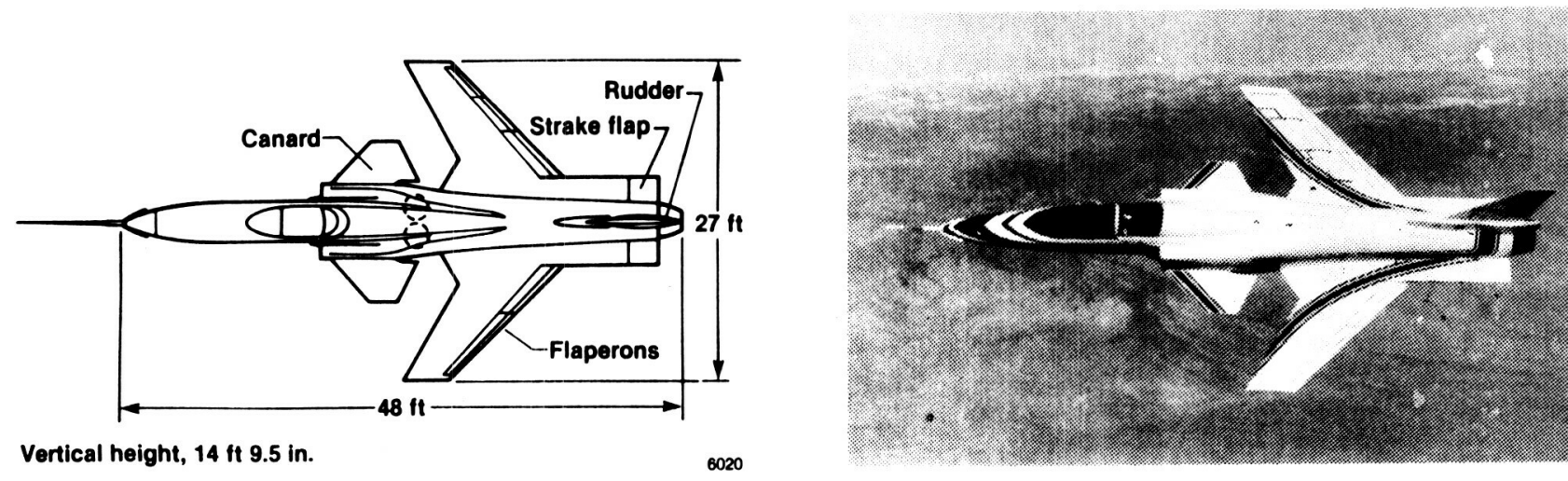

Fig. 1 X-28A advanced technology demonstrator. 


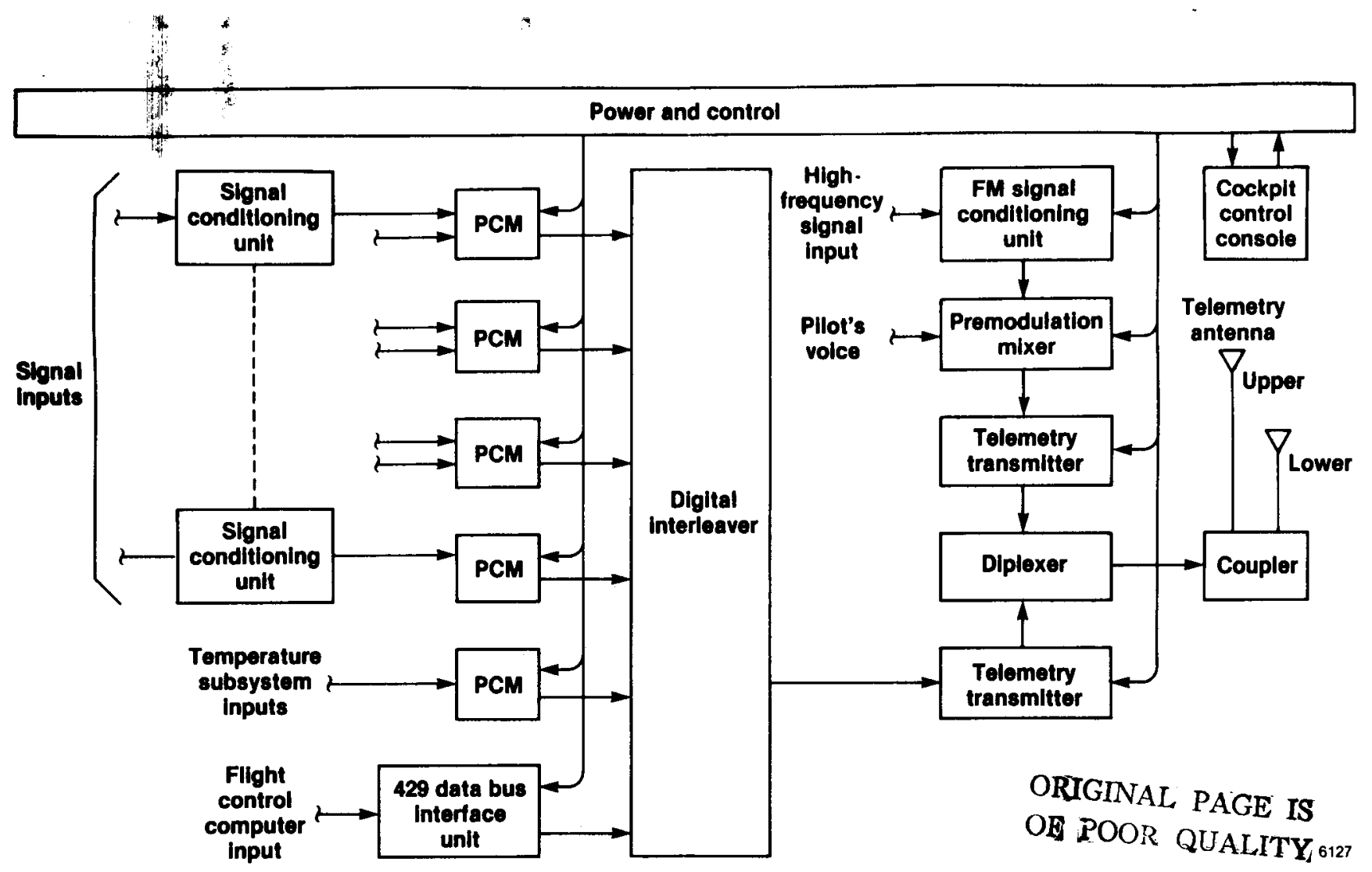

Fig. 2 X-29A on-board data aoquisition eystem.

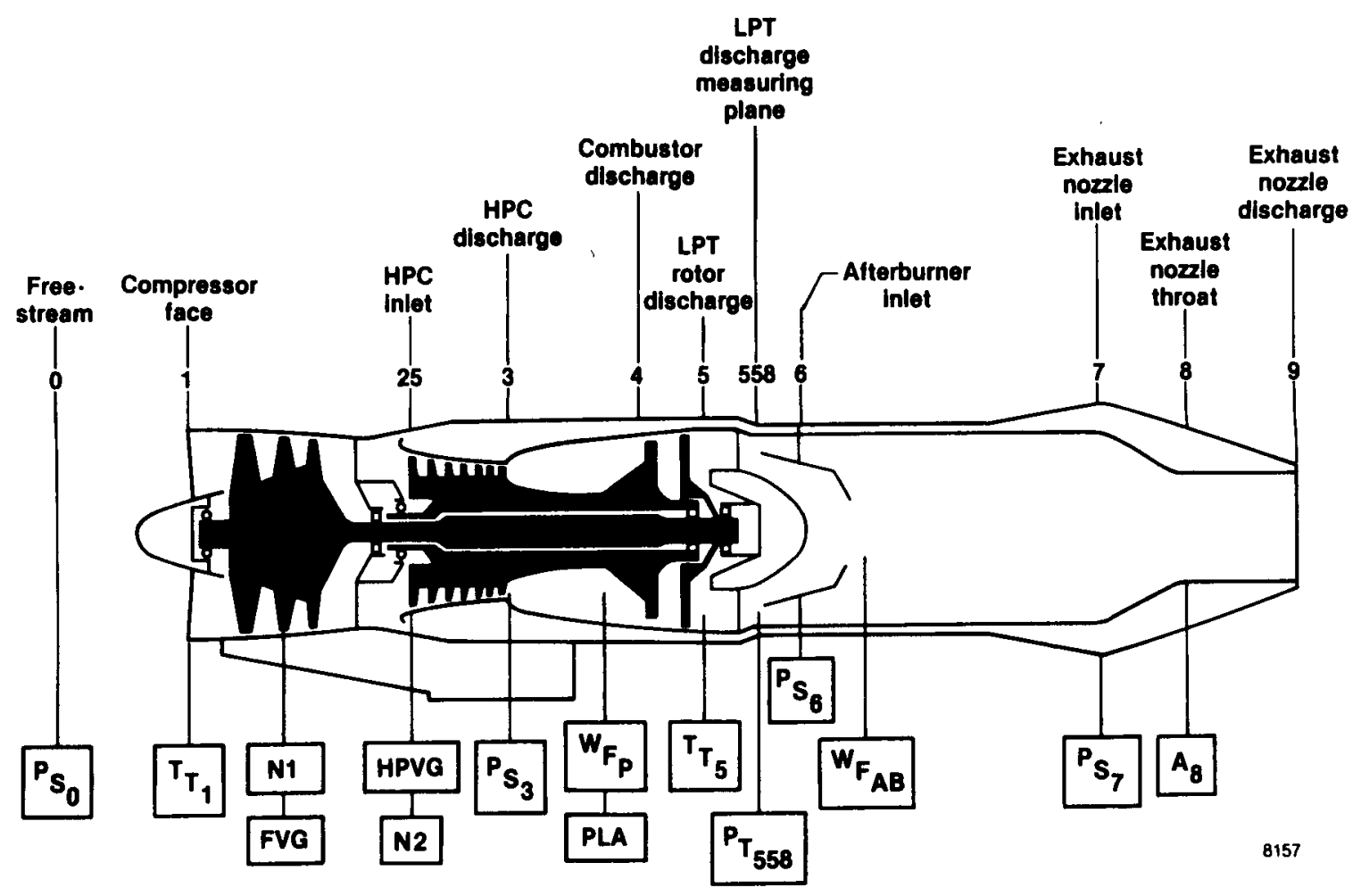

(a) Bngine station and senvor looations.

Fig. 3 Bngine instrumentation aysten. 


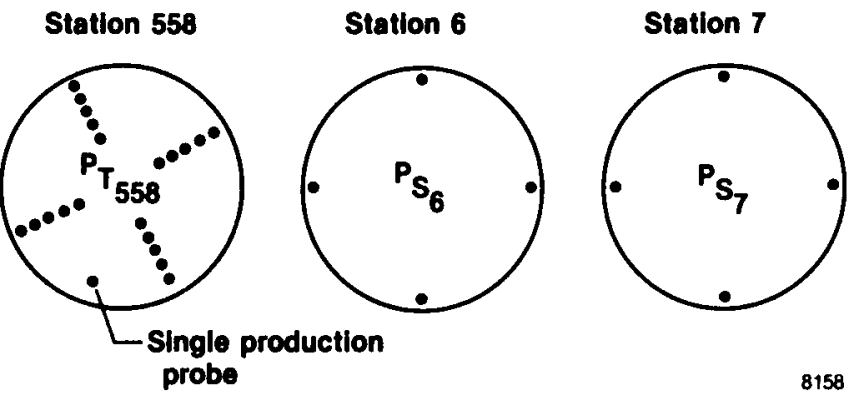

(b) Location of engine pressure rakes used by the Combev thruet teohniques.

Fig. 3 Concluded.

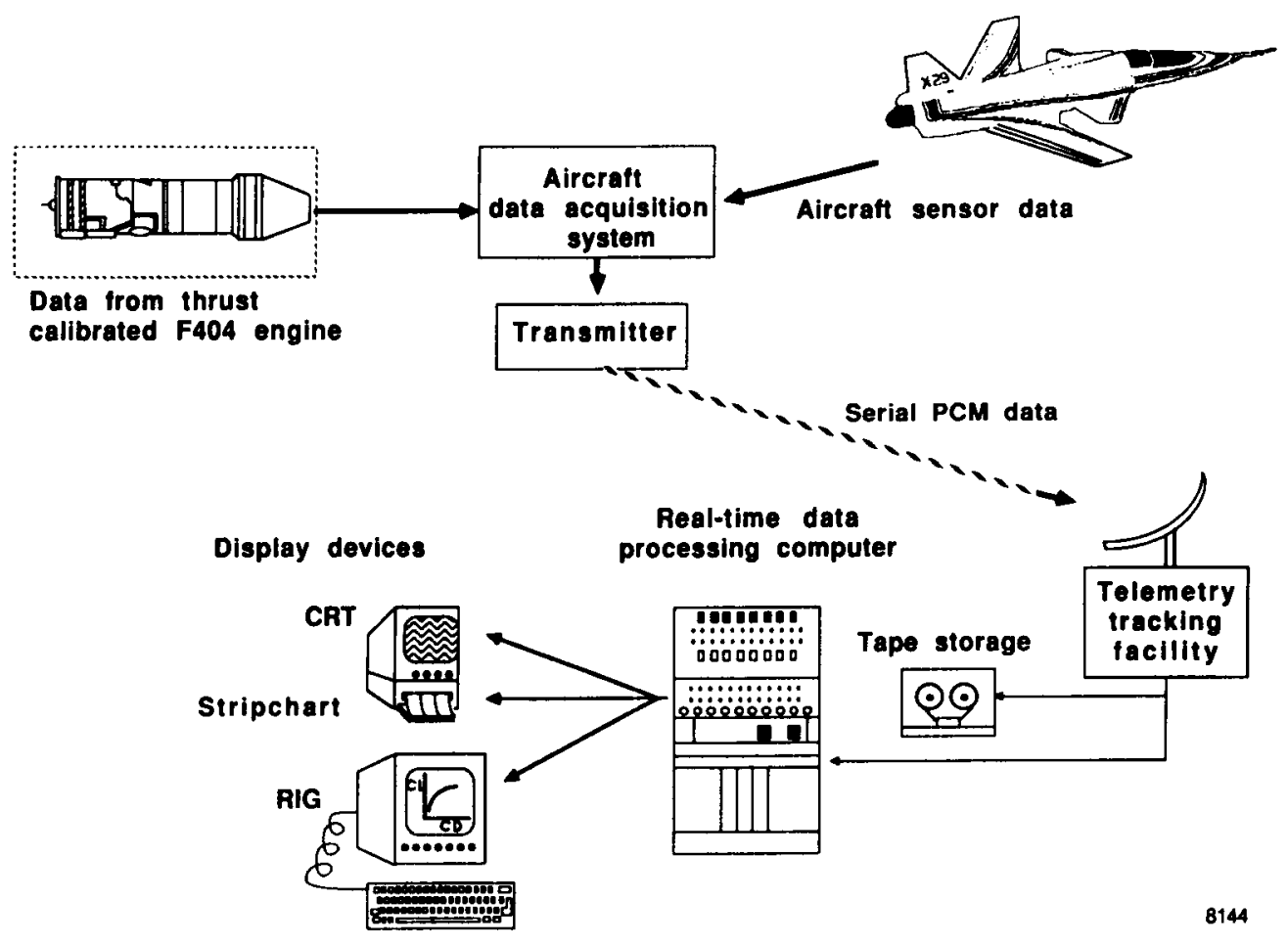

Fig. I X-28A real-time performanoe data system. 


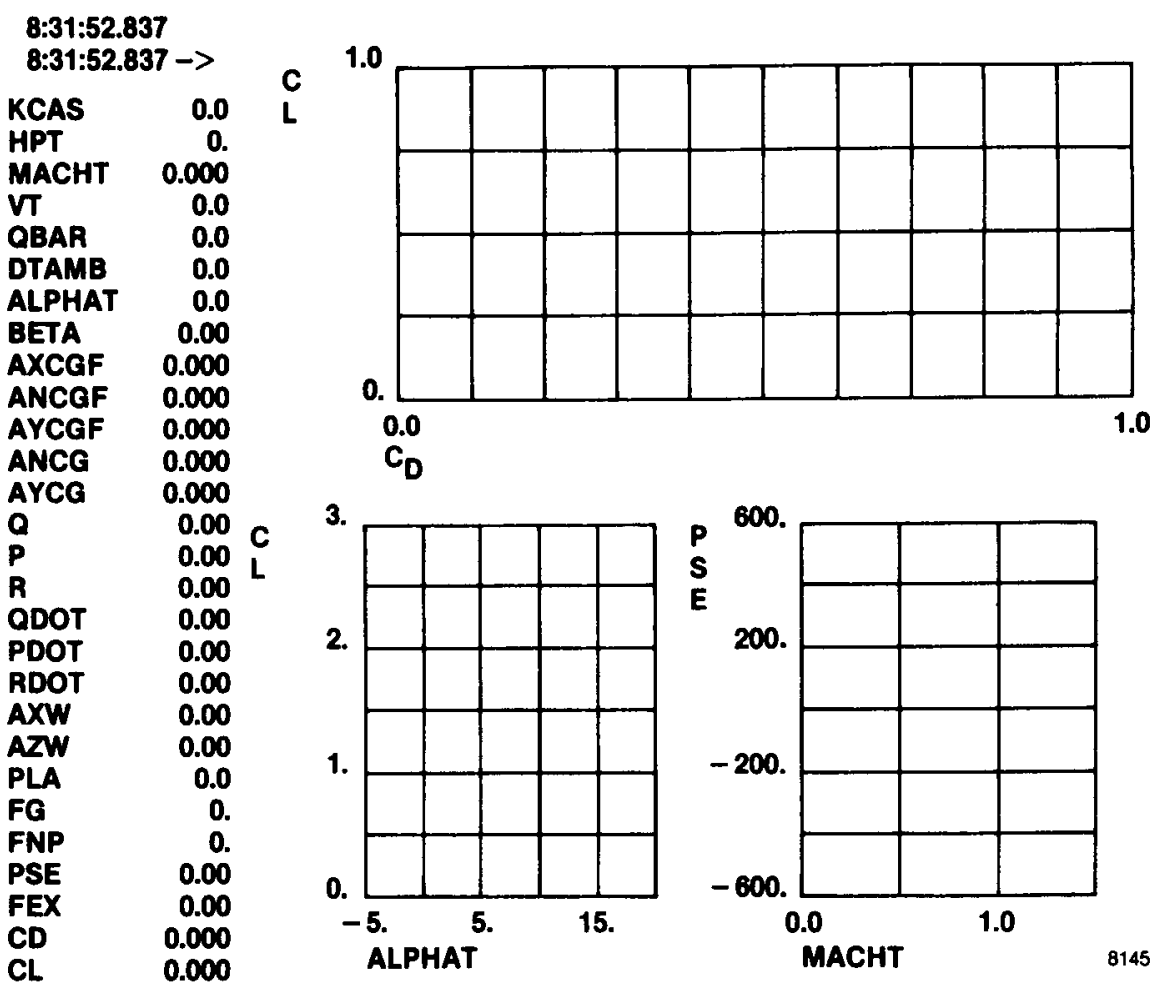

Fig. 5 Sample RIG display format.

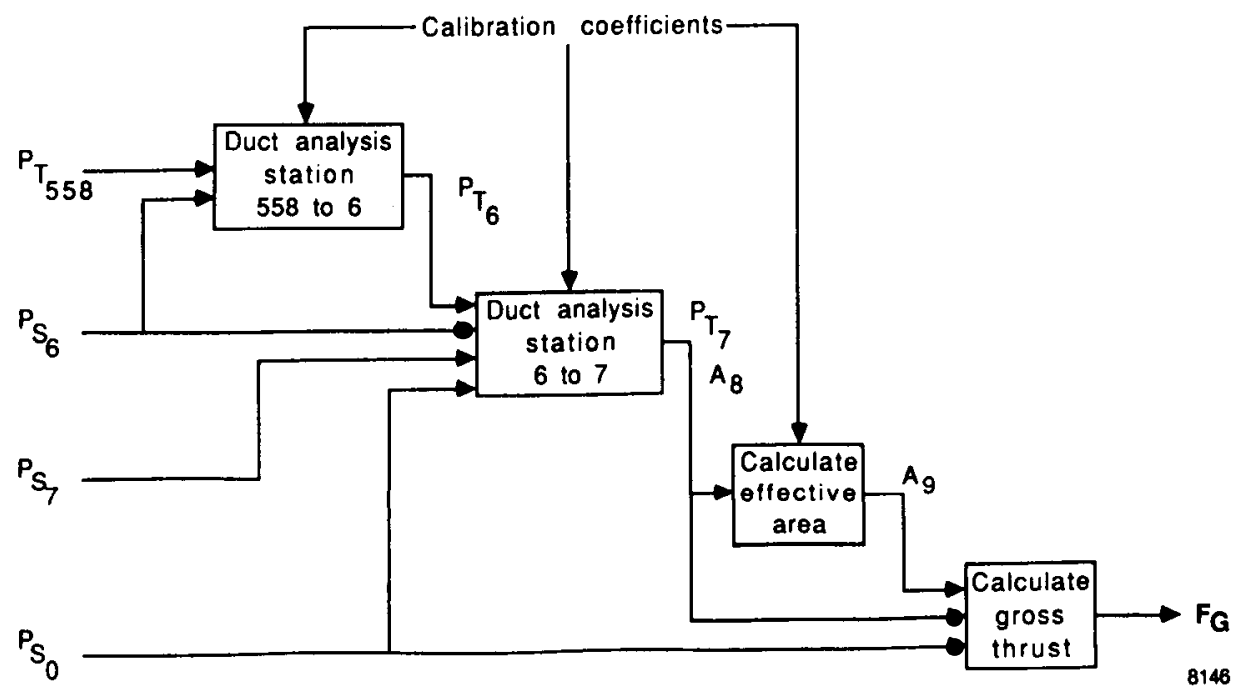

Fig. Flow ohart of the SGTM.

ORIGINAL PASE IS

OF POOR QUALITY 


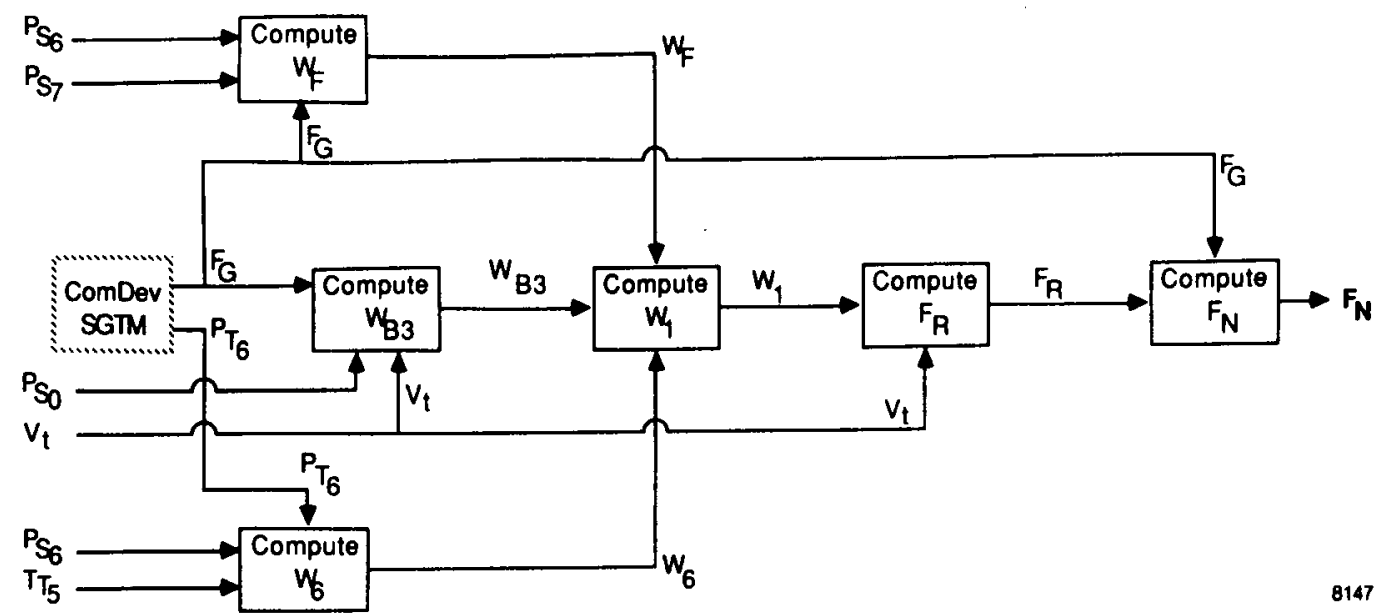

Pig. 7 Fow chart of the SWIN.

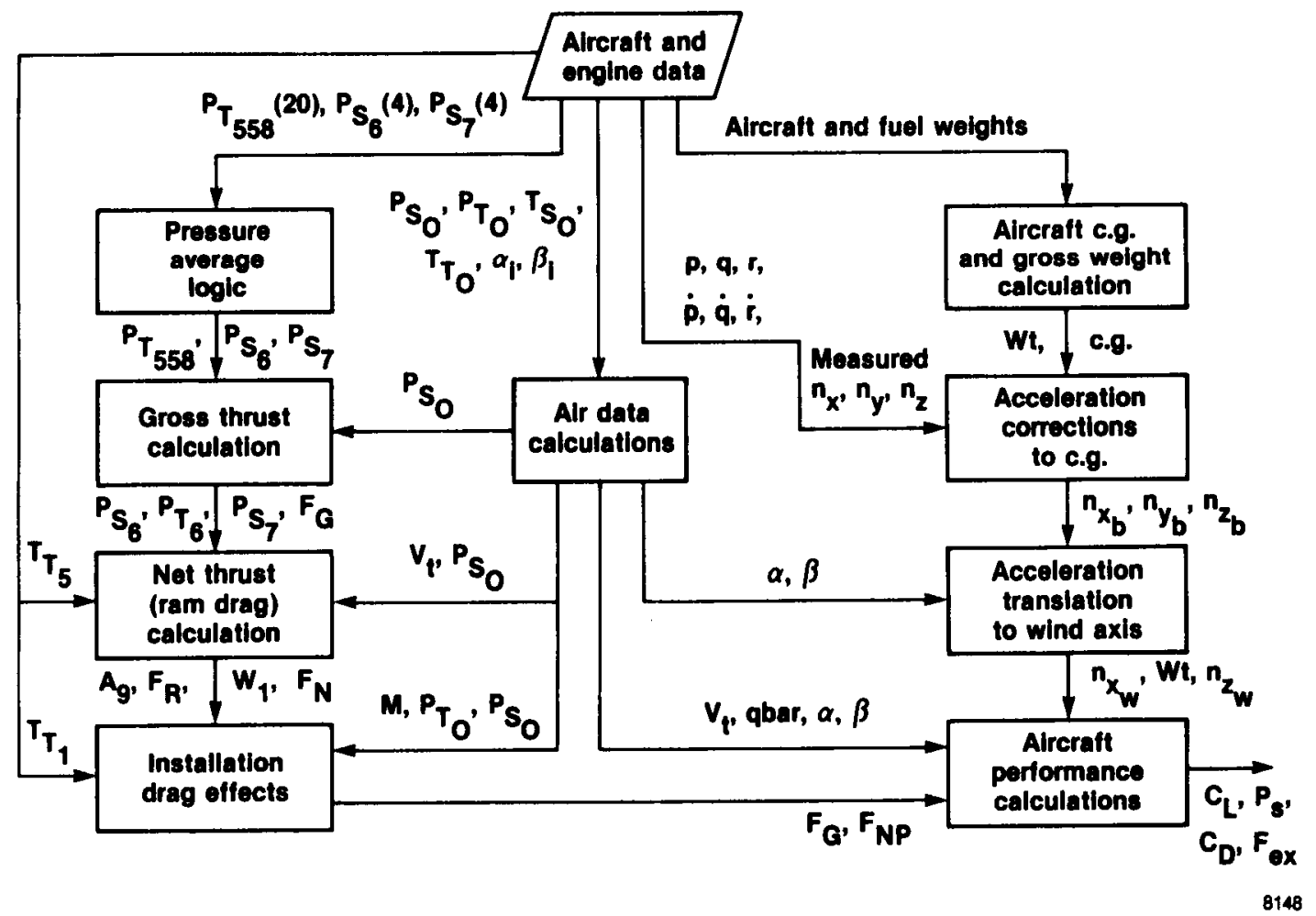

Fig. $8 x-29$ real-time performance oaloulation flow chant. 


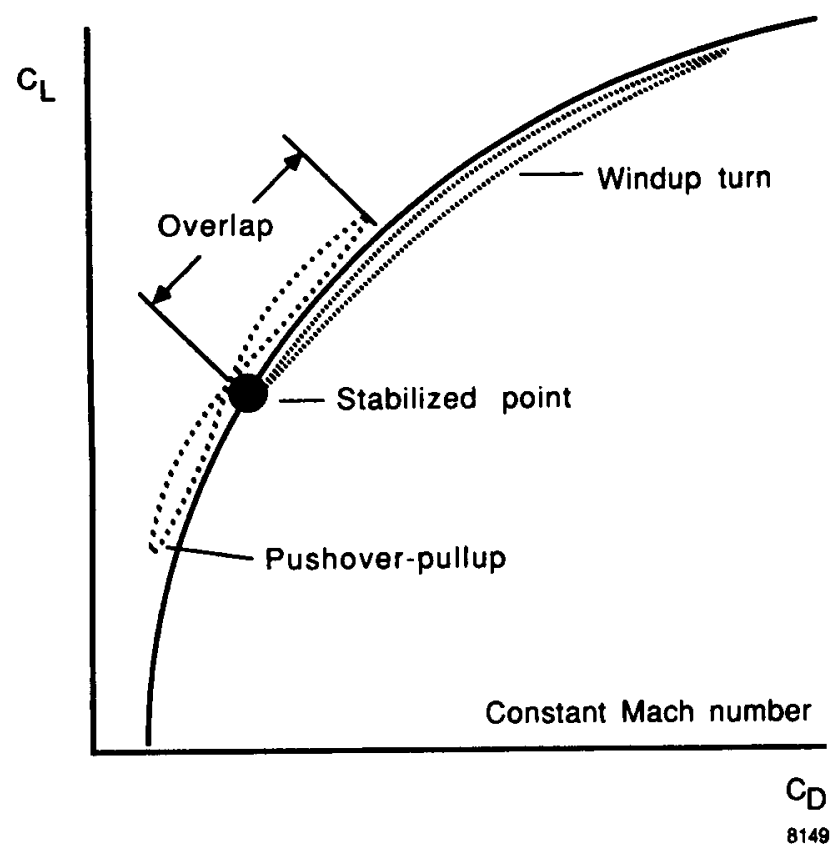

Fig. I schematic of maneuvere to define a drag polar.

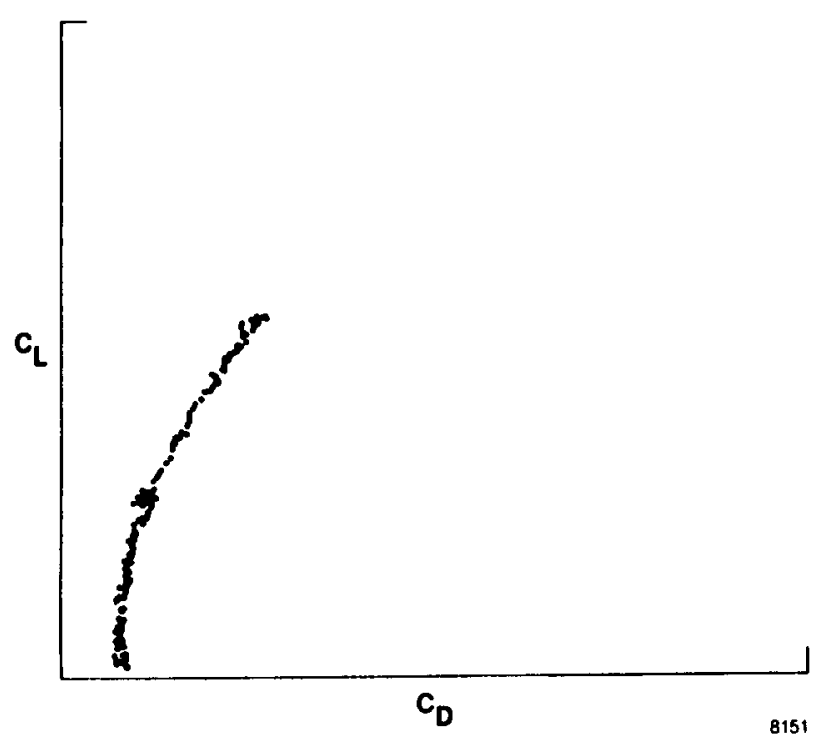

(a) Pushover-pulzup.
Drging are IS

DE POOR QUALITY

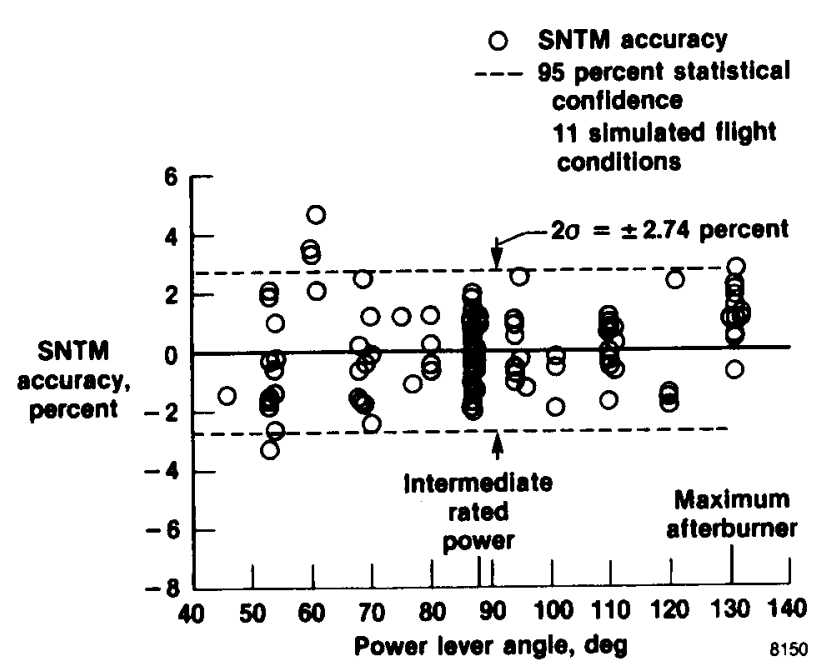

Fig. 10 Aoouraoy of the SNTN determined at Lewis PSL faoility.

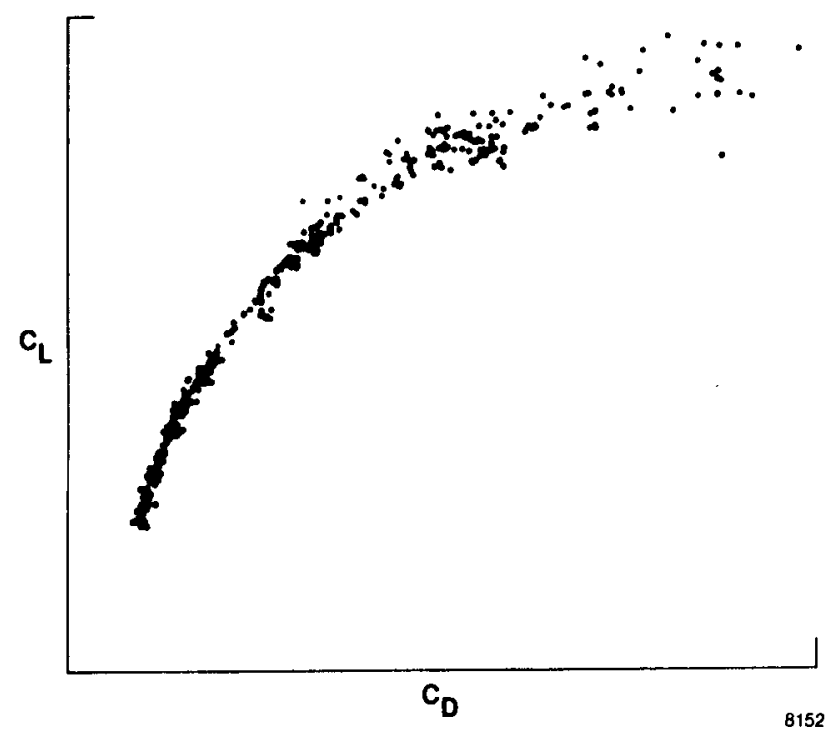

(b) Windup tum.

Fig. 11 Examples of real-time airoraft performance data. 


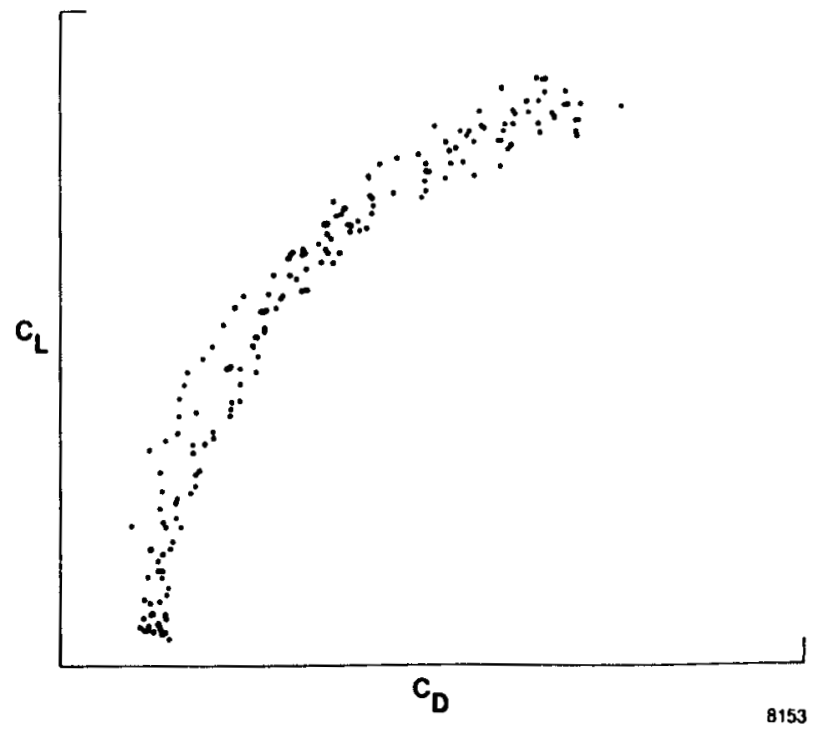

(a) Pushover-pullup.

Fig. 11 Concluded.

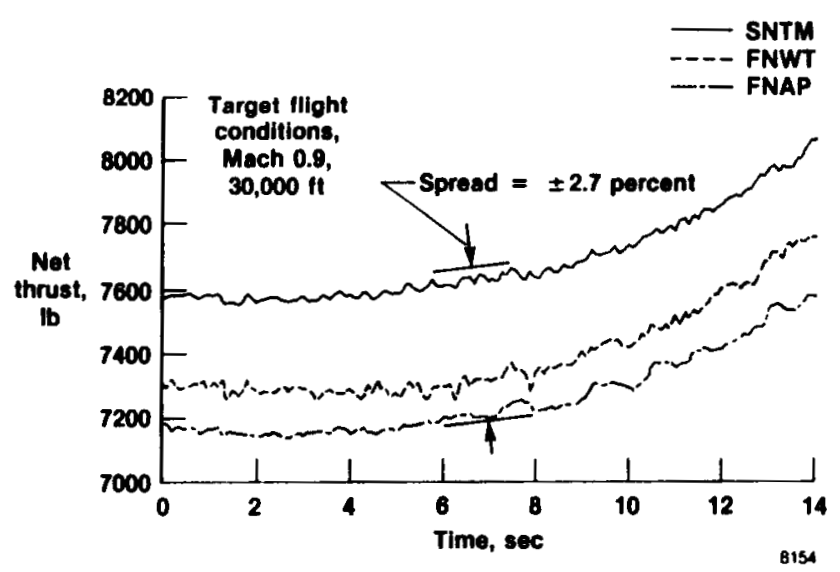

(a) Windup turn, maximum power, 0.8 mach, $30,000 \mathrm{ft}$.

Fig. 12 Comparioon of in-flight net thrust calculated by three msthods. 

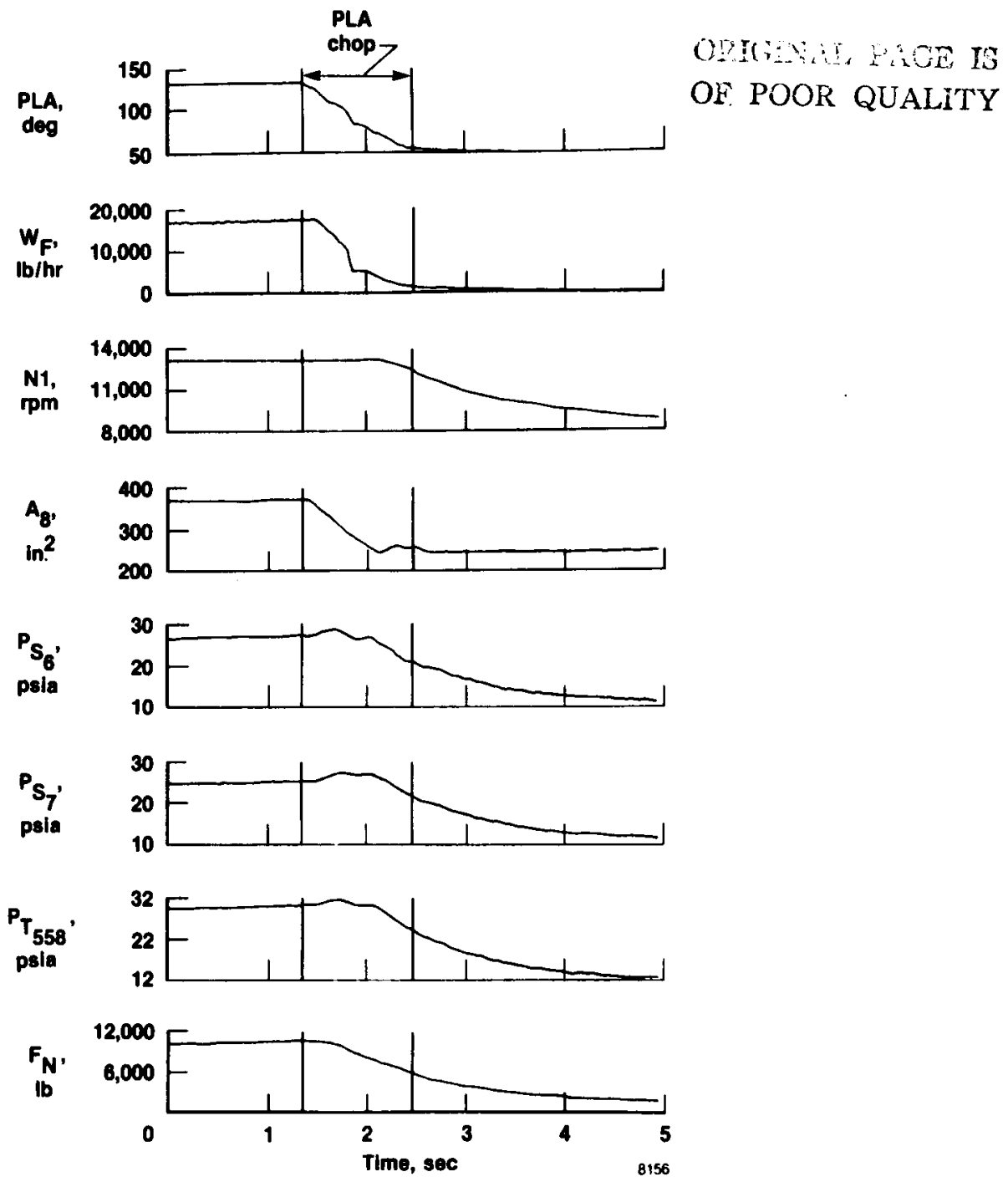

Fig. 13 Dynamic response of the SGTH to a PLA chop, 0.7 wach, $23,000 \mathrm{ft}$. 


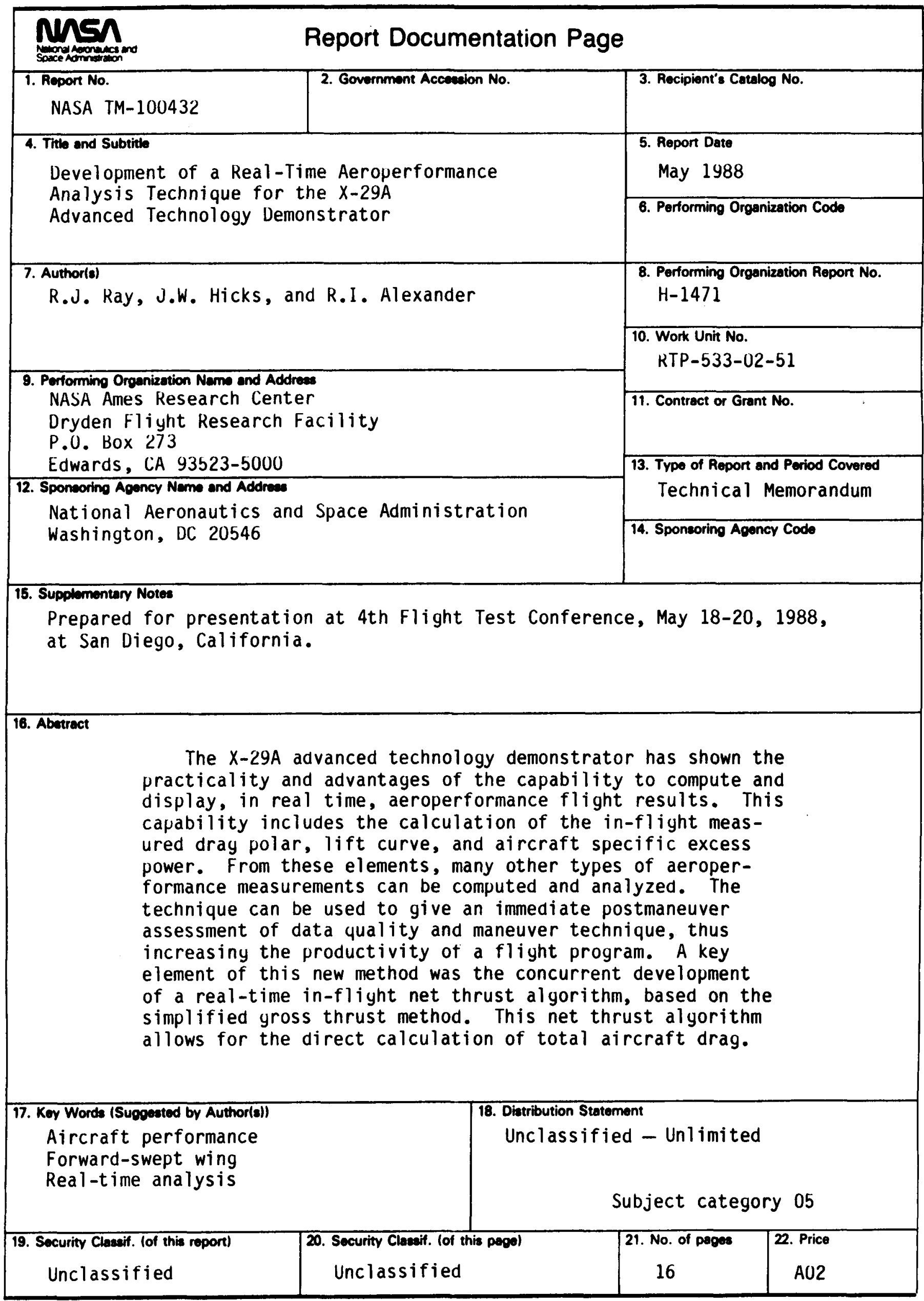

